\title{
LA LENGUA COMPAÑERA DEL IMPERIO (a)
}

\author{
Historia de una idea de Nebrija en España y Portugal
}

La máxima afortunada, que Nebrija acuñó en la dedicatoria - prólogo a su Gramática castellana, I492, ha rondado mi memoria desde los bancos universitarios, aunque sólo paulatinamente he ido averiguando su genealogía y deslindando sus circunstancias. Lecturas posteriores me fueron revelando que el concepto derivaba de las Elegantiae, del humanista italiano Lorenzo Valla; había sido resumido en frase muy parecida por el jurista aragonés Gonzalo García de Santa María antes de hallar hospedaje en las páginas de Nebrija para definir las ambiciones culturales de la expansión española; y que, cargado ya con el nuevo sentido que le daban los descubrimientos y conquistas, había sido acogido por los gramáticos portugueses Oliveira y Barros, que, a su significado político y nacional, habían ido añadiendo los matices afines de asimilación colonial y de misión cristiana. El concepto de relación entre la lengua y el imperio se desplegaba en abundantes permutaciones según el fondo histórico a que se aplicaba. I a ampliación del horizonte iba convirtiendo el tópico inicial de Valla en una cambiante perspectiva que ofrecía una interesante visión de la lengua como instrumento político y cultural. La historia sucesiva se ordenaba en un prólogo y tres jornadas: Italia o el lugar común; Aragón o la unidad hecha desde la corte; Andalucía - es decir, Nebrija - o la integración nacional; Portugal o la expansión cultural y misionera.

Don Ramón Menéndez Pidal, ell dos estudios -el reciente La Lengua en tiempo de los Reyes Católicos (CHi, enero-febrero, I950) y El lenguaje del siglo XVI (Cruz y Raya, I933) - ha situado esta fórmula y las ideas de Nebrija dentro de las contiendas lingüísticas y contexto literario que la envuelve. Los nuevos datos por mí allegados, si de una parte quitan a Nebrija la primacía de la invención, de la otra amplían sus

a) Comunicación presentada en el simpósio de Filologia Románica de Río de Janeiro, agosto de $195^{8}$. 
fecundas resonancias. Porque la vida de un tópico es muy diferente de lo que imaginó $\mathrm{R}$. Curtius cuando llama a los pensamientos de los humanistas - a propósito de un Jibro de Eugenio Garin - trivialidades (= Platitueden) o "elegantes variaciones sobre lugares comunes que se venian usando desde la antigüedad y eran familiares a la Edad Media" ("elegante Variationen ueber Gemeinplaetze... die fuer thetorische Uebung seit dem Antike gebraucht wurden und dem ganzem Mittelalter vertrant waren") ${ }^{1}$. En el manantial, el tópico de Lorenzo Valla era más que un fantasma retórico, y en los escritores peninsulares, al contacto de las nuevas tareas, tomaba un alma nueva y un sentido original.

I a gloria de Roma, trompeteada incansablemente por los humanistas italianos, provoca una noble emulación. I,os hombres de la península se ufanan de superarla en las hazañas y aspiran a emularla en las letras. La escuela de latín se transforma insensiblemente en escuela de romance y la lengua de Roma, ptimero piedra de toque, pasa a ser trofeo con que se enriquece el arsenal de la española o portuguesa. E1 proceso de emancipación se observa igualmente en la obra de los filólogos que, apoyándose en las enseñanzas tanto de los antiguos como de los humanistas recientes, alzan el edificio de las gramáticas nacionales.

Lorenzo Valla, tan ligado a los reyes de Aragón, que para ellos compuso su Historia del rey Fernando, nos dejó en sus Elegantiarum libri VI, bajo las apariencias de un simple manual de latinidad elegante, uno de los libros turbadores que iban a proyectarse hacia el futuro y despertar la reflexión de hombres como Nebrija y Erasmo. En él aprendieron el paso de la palabra al pensamiento, de la filología a la historia y la teologia.

El texto se reparte en seis trozos preliminares de alta retórica y seis libros de pencsa crudición, de sutiles menudencias e interpretaciones de vocablos. Los seis prefacios desbordantes de entusiasmo son como seis manifiestos de agresivo humanismo en que Valla guerrea contra la barbarie y pregona la nobleza de las tareas gramaticales. El más clamoroso y sugestivo es el del libro primero en que, glorificando a la Roma madre de las leyes y mecenas de las letras, proclama que el Imperio Romano,

1 Bibliothèque d'Humanisme et Renaissance, $\mathrm{X}, \mathrm{I} 948, \mathrm{p} . \mathrm{I} 88$. No es mi objeto reseñar atisbos de este lugar común antes del humanismo. Ya el cordobés Ibn Hazm a mediados del siglo XI había dicho que «lo que fija y conserva la lengua de una nación, así como sus ciencias y su historia, es únicamente la fuerza de su imperio político, acompañado del bienestar alegre y del vagar de sus habitantes». M. Asín, Al-Andalus, 1939, IV, 278. (Citado por A. CASTro, La vealidad histórica de España, México, 1954, p. 475.) 
derrumbado por el tiempo en la esfera política, se mantiene vivo en la esfera de la cultura y de la lengua. Las naciones conquistadas, que han sacudido el yugo político, conservan agradecidas la herencia espiritual. Roma sigue imperando donde impere la lengua romana. He aquí algunos trozos que más nos interesan ${ }^{1}$ :

"Cuando medito a menudo sobre las hazañas de nuestros antepasados cotejándolas con las de otros reyes o pueblos, me parece que los nuestros aventajaron a todos los demás tanto por la extensión del Imperio como por la difusión de la lengua... Obra esta mucho más gloriosa y mucho más bella que el mismo imperio." (Con la lengua llevaron las artes liberales, el derecho, la sabiduria. Los pueblos sometidos sacudieron el yugo de las armas, pero mantuvieron el yugo de la lengua. I os romanos cultivaban a la par de las armas las letras, premiaban a los que las profesaban, alentaban a los súbditos a que hablasen latín.) "Hemos perdido Roma, hemos perdido el reino y señorío, no por culpa nuestra sino de los tiempos. Pero gracias a este brillante seĩorio (de las letras), reinamos aún en gran parte del mundo. Nuestras son Italia, Galia, España, Germania... y otras muchas naciones. Porque el imperio romano está donde quiera que señorea la lengua de Roma." ( $Y$ con palabras acaso sugeridas por Plinio, que, clogiando a Cicerón, en su Historia Natural, afirmaba que más valia ensanchar los límites del ingenio que del imperio romano, convocaba a la tropas de gramáticos y literatos para que defendiesen e ilustrasen la lengua latina.)

Este ensalzamiento de las letras a costa de las armas, muy en su punto en una Italia ocupada por españoles y franceses, estaba enteramente dislocado en la España de los últimos días de la guerra de Granada, entre I486-I492, cuando se estampan las obras en que Micer Gonzalo García de Santa María y Antonio de Nebrija glosan, o, mejor, replantean, a la española, ciertas sugerencias de Valla. Los guerreros están realizando el sueño de la reconquista. Alfonso de Palencia, el anciano humanista, traduce al español las Vidas de Plutarco (I49I), para espolear al heroísmo una nobleza que ignora el latín. Hugo Urríes vierte -del francés y no del latín- a Valerio Máximo (Zaragoza, I495) intercalando entre las hazañas romanas las recientes hazañas de la guerra de Granada.

En cambio brindaba a los españoles, ante quienes se abrían mágicamente las puertas de un futuro imperio, reflexiones sobre el curso paralelo de la lengua y el poderío: cabía destronar al Imperio Romano

1 Más cómodanente que en las numerosas ediciones del siglo xir pueden leerse loy estos seis prólogos - texto latino y traducción italiana enfrentados- en Prosatori latini del Quattrocento, a cura di E. GARIN, Milano-Napoli (La letteratura italiana, Storia e testi, vol. 13), pp. 595-60r. Acerca del papel central de las Elegantiae en la obra de Valla, véase Franco GAETA, Lorenzo Valla, Napoli, 1955. 
de su puesto eminente, darlo por caducado, y aplicar la retórica relampagueante de Valla a la situación española, trazando al venidero imperio un programa de política lingüística.

Las Elegantiae, de Valla, circulaban por Aragón. Pedro Tolón, limosnero -o caritatero - de dos arzobispos, lega al morir, en el inventario de su biblioteca, hecho en I489, unas Elegantiae Laurencii ${ }^{1}$. Su grande amigo micer Gonzalo García de Santa María, al testar el 13 de mayo de I5I9, en avanzada edad, manifiesta que posee "dos volúmenes de obras de Lorenzo de Valla en paper, de mano" (= manuscritas). Erran volúmenes parejos, repetidos. Hacia I490, al leer el prefacio de Valla al libro primero de las Elegantiae, micer Gonzalo, que reside en Zaragoza $\mathrm{y}$ es jurisconsulto del rey Católico Fernando, cree atisbar una idea eficaz, una solución teórica al candente problema de política cultural que plantea la unificación de dos reinos que hablan diferente lenguaje: Aragón y Castilla. Ia solución -dolorosa acaso para un aragonés- se le aparece clara: Aragón debe adoptar como lengua de cultura la lengua de Castilla, la lengua de la corte que reside en Castilla.

E1 programa de esta unificación lo expuso en un extraño lugar: al frente de las vidas de los padres del yermo que acababa de traducir e imprimía en Zaragoza. Antes de glosar este importantísimo documento, hasta hoy ignorado por los investigadores, hemos de decir unas palabras sobre el misterioso, enigmático Micer Gonzalo.

Micer Gonzalo descendía de la más gloriosa familia de conversos castellanos que había dado ya dos celebrados escritores: Pablo de Santa María, obispo de Burgos y apologista del cristianismo contra el judaísmo; Alonso de Cartagena, su hijo segundo y sucesor en la silla episcopal, que, siendo embajador en la corte portuguesa por los años de I42I-2, había compilado, para el infante Don Duarte, un Memorial de virtudes y traducido la Retórica, de Cicerón 2. Micer Gonzalo, a pesar de su cristianismo, debía guardar en el ambiente familiar usos y tradiciones hebraicas, pues fue penitenciado tres veces por la Inquisición. Leves serían los pecadillos, ya que las reincidencias eran severísimamente castigadas. Para su sepulcro compuso un orgulloso epitafio en que se ufana de su latinidad: «Post quam Gondisalrus Garcia de Sancta Maria, eloquentissimus juris-

1 Vide Manuel Serrano y Sanz, Testamento de Gonzalo Garcia de Santa Maria, BRAE, I, I914, pp. 474-5.

2 Luciano Serrano, Los conversos D. Pablo de Santa Maria y D. Alfonso lie Cartagena, Madrid, 1942, pp. 128-7, 249; Francisco CAN'TERA, Alvar Garcia de Santa Maria y su familia de conversos, Madrid, 1952, pp. 20r, 448. 
consultus, e vita migravit, non parvam in Hispania latine littere fecere jacturam\%. A su pluma se deben dos versiones de importancia cardinal para la piedad española: los Evangelios y epistolas (Zaragoza, I485) ${ }^{1}$ y Las vidas de los sanctos religiosos (Zaragoza, s. a. I486-9I) ${ }^{2}$.

Las vidas de los santos religiosos o Vitas patrum (así son intituladas ordinariamente) tuvieron una esplendorosa carrera; inspiraron los juegos infantiles de Santa Teresa y su hermano; dieron materia a pintores y modelo a ermitaños aficionados, acabando por ser prohibidas

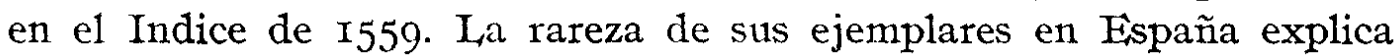
que su sorprendente prólogo haya escapado a los estudiosos de la lengua. Extractaré los fragmentos más jugosos ${ }^{3}$ :

«Después de la traslación que fezimos poco ha de los evangelios, donde sta scripta llena e cumplidamente la ensenyança divina... muy conveniente cosa me pareció como práctica de aquella doctrina trasladar las vidas de los padres que primero moraron en el yermo". (La frase "poco ha fezimos" sitúa la impresión en las inmediaciones de $\mathrm{I}_{486}$, antes de la fecha tope I49I marcada por los bibliógrafos.) Pasa micer Gonzalo al problema del estilo en las traducciones y afirma: "E porque el real imperio que hoy tenemos es castellano, y los muy excellentes rey e reyna nuestros senyores han escogido como por asiento e silla de todos sus reynos el reyno de Castilla, deliberé de poner la obra presente en lengua castellana. Porque la fabla comúnmente, más que otras cosas, sigue al imperio. E quando los prín-

1 Edición perdida. La segunda de Salamanca, I 493, existente en la Biblioteca Universitaria de Uppsala, ha sido reimpresa y prologada por I. CoLLIJIN y E. STAAF: Evangelios y epistolas con sus exposiciones en romance, segín la versión castellana del s. XV, hecha por G. G. de S. M., del texto de Guillermus Parisensis "Postilla super epistolas et evangelias Uppsala-Leipzig, rgo8. Esta versión fue retraducida al portugués e impresa en Porto, 1497 (Bibliogr. geval portug., Lisboa, I95 I, t. I, páginas 22 $1-30$ ). El tosco estilo de esta obra primeriza fue revisado en Toledo, I5 12 , por fray Ambrosio Montesino, que en la dedicatoria a Don Fernando afea el lenguaje $y$ anuncia la ha reducido al romance de Castilla "porque estaba muy corrompida, confusa e disforme, assí por la impropiedad y torpedad de los vocablos... como por la confusión y escuridad de las sentencias. La qual en algunos passos más parecia scriptura de bárbaros que de fieles" (PEREZ PASTOR, La imprenta en Toledo, Madrid, I887, p. 70.) Así elegantizada circuló en múltiples tiradas hasta que la Inquisición la vedó en el Indice de 1559.

2 HAFBLER, Bibliografía ibérica, II, 335 (5); STILIWELI, Incunabula in American Libraries, Nueva York, I940, H2I 5; F. VINDEL, El arte tipogrático en España durante el siglo XV. Dudosos... Adiciones y correcciones, Madrid, I95I, pp. 233-34, reproduce la primera página del prólogo y la última del libro.

3 Un día espero ocuparme del autor y de su libro. Ia comparación de las sucesivas ediciones muestra en qué alto grado la imprenta y los impresores alisaron, igualaron $\mathrm{y}$ pulieron las aristas dialectales del castellano y modernizaron los textos. 
cipes que reynan tienen muy esmerada e perfecta la fabla, los súbditos esso mismo la tienen. E quando son bárbaros e muy ajenos de la propiedad del fablar, por buena que sea la lengua de los vassallos e subjugados, por discurso de luengo tiempo se faze como la del imperio. $\mathrm{E}$ assí fue por los godos e franceses la lengua latina quando occuparon a Roma tan estragada, que ella junto con la misma scriptura en gran parte pereció. He yo fecho mención de la lengua latina assí como emperadriz, guia e govierno de todas las otras". (A continuación rechaza por arcaizante la lengua de las antiguas crónicas y de las Siete Partidas, por grosera y áspera la de Galicia, Vizcaya, Asturias y hasta la Tierra de Campos, es decir, Castilla la Vieja y parte de León, por morisca la de Andalucía): "Que ni aquellas, ni lo mu andaluz es hovido por lenguaje esmerado. Ca lo uno de muy gruesso e rudo se pierde, e lo otro de muy morisco en muchos vocablos apenas entre los mismos Castellanos se entiende. Ca el vocablo deve ser como la moneda... que en ninguna tierra de las mismas del príncipe que la batió se rehuse: y lnego que el mote o palabra es de muy andaluz tan cerrada que amalavés en el mismo Reyno, salvo en aquel logar sólo donde le fablan, se entiende, luego le rehusan como a dinero que tiene cunyo e forma no conocida. F porque las cortes delos reyes van por todo e toman de cadaqual lo mejor, e los que fablan delante de reyes e príncipes trabajan de poner sus razones en los mejores términos que saben e alcançan, en cada logar es hovida la lengua dela corte por de todas la mejor e más encimada. E la misma differencia e ventaja que lieva la fabla del hombre de pro a la del villano e soez, haun que hayan ambos nacido en una misma ciudad e barrio, aquella lieva la de la corte a la delas otras villa e ciudades de todo el reyno. Por quanto aquella assí por la noble criança e destrados como por la gente de consejo e letrados e embaxadores que en ella van e concorren de continuo, es como piedra de toque de todas las otras lenguas dela tierra. E assi en Francia e en otras provincias la mejor lengua de todas es la de la cortem.

La corte resume y condensa tres altos valores del lenguaje: el de la historia, el de la cultura y crianza, el de la comunicación e inteligibilidad. Toledo, ordinaria residencia de los reyes en que el autor está sin duda pensando, debe su primacía lingüística no al favor de la naturaleza, sino al de la historia que la ha ido puliendo gracias al trato de los palaciegos. Los reyes y su séquito, muy andariegos en aquella sazón, han ido recogiendo por doquiera que iban y llevando a la corte los más esmerados hábitos y usos de hablar o escribir. Andalucía, infestada de términos moriscos y ajenos al resto del país, no puede competir con Toledo. Micer Gonzalo, humanista que considera a la lengua latina como "emperadriz, guía e govierno" condena vigorosamente el arabismo. Escribiendo antes de que aparezca la primera Gramática castellana, recalca (en un pasaje que hemos omitido) que uel que tiene de ella entero conocimiento, luego que entra en rastro de otra cualquiere, va más suelto e denodado por ella que el mismo que en ella nació. Ca sabiéndola por razón e por arte, sabe muy bien conoscer de qué quilate es cada vocablo». La revolución de Nebrija consistirá en invertir esta posición dominante, 
gracias a la pedagogía, de la lengua latina, enseñar el castellano por razón $e$ por arte en los comienzos, restableciendo el natural progreso de lo sencillo a lo difícil. Dirá Nebrija: "Después que sintieren bien el arte del castellano... cuando passaren al latín, no avrá cosa tan escura que no se les haga mui ligera» ${ }^{1}$.

Micer Gonzalo no carece de precursores en sus opiniones, 10 mismo sobre la lengua cortesana que sobre la lengua rústica y el arabismo. Sobre la lengua cortesana creo percibir dos ecos apagados de Dante cuando en su De vulgari eloquentia diserta sobre el vulgare aulicum o curiale. Dice Dante ${ }^{2}$ : "Si aula totius regni communis est domus... quicquid tale est ut omnibus sit commune, nec proprium ulli, conveniens est ut in ea conversetur et habitet... hoc nempe videtur esse id de quo loquimur vulgare». O sea: «Si la corte es casa común del reino entero... como sea cosa común y no privativa de nadie, conviene que en ella se tenga trato y se viva: tal parece ser la lengua vulgar de que hablamos». $Y$ más tarde compara a la curia con la balanza que regula y mide nuestro obrar: "Curialitas nihil aliud est quam librata regula eorum quae peragenda sunt: et quia statera huiusmodi librationis tantum in excellentissimis curiis esse solet». Resonancias lcjanas me parecen la exaltación de la lengua cortesana como única común y no privativa, mudando la imagen de la casa de todos por la moneda; y la comparación de la corte con una piedra de toque del hablar, parecida a la imagen dantesca de la balanza. Las reminiscencias — si, como opino, las hayhan servido apenas para tensar el resorte del propio razonamiento, condicionado por la coyuntura ascensional de la monarquía española. Mientras Dante plañe en Italia la ausencia de una corte, micer Gonzalo ve, en la medida humana, realizada la corte ideal de los juristas por los dos Reyes Católicos Fernando e Isabel. E1 vulgarismo fue relegado por la literatura a los pastores sayagueses de Mingo Revulgo, de la Vita Christi de Iñigo de Mendoza; de los autos de Encina y su escuela, de los villancicos. Explícitamente lo combate el autor del vocabulario castellano,

1 Gramática castellana, ed. de Pascual, Galindo y Luis ORITI, Madrid, I946, p. Io.

2 Uso la edición de ARISTIDE Marigo, con traducción y comento: DaNTE ALIGHIER, De vulgari eloquentia I XVIII, pp. I52-4 (Florencia, I948). Acerca del problema y su historia posterior, véase P. RAJNA, La lingua cortigiana (en Miscellanea linguistica in onore di G. Ascoli, Turin, I9oI), pp. 295 ss. Sobre el encuadramiento de la discusión, es útil y sucinto R. A. HALI, The Italian questione della lingua, Chapell Hill, I942. 
manuscrito del siglo xv, glosado recientemente por Fernando Huarte ${ }^{1}$ El menosprecio a lo "morisco", rasgo de incalculable consecuencias, se acentúa en los días de los Reyes Católicos. Juan de Lucena lo reprende en un obscuro trecho de la Vita beata y Alonso de Palencia llega a censurar en Enrique IV el que montase a la gineta, es decir, al uso moro. E1 uso de arabismos sería esgrimido como argumento contundente contra el toledanismo por el médico Francisco López de Villalobos. La extirpación progresiva del arabismo privaría a la lengua castellana de uno de sus más expresivos recursos de contraste y variación, que reviviría tímidamente para toques de color local en Ginés Pérez de Hita y los romances moriscos.

Sobre Antonio de Nebrija lo esencial está dicho en las páginas de don Ramón Menéndez Pidal. Yo querría esclarecer dos puntos: su entronque con Lorenzo Valla y su concepción de la lengua como criatura orgánica, ligada a la vida y muerte de los imperios, paradójicamente estabilizada y como eternizada por el arte de gramática.

E1 prólogo de su Gramática castellana conjuga y une esquemas e ideas del de las Elegantiae con reminiscencias, redondeadas y elaboradas, de micer Gonzalo. Oigámosle: "Cuando bien pienso, mui esclarecida Reina, i pongo delante de los ojos el antigüedad de todas las cosas que para nuestra recordación i memoria quedaron escriptas, una cosa hallo i saco por conclusión mui cierta: que siempre la lengua fue compañera del imperio y de tal modo lo siguió que juntamente començaron, crecieron y florecieron y después juntamente fue la caída de entrambos». Lorenzo Valla, calcando un esquema de Cicerón -el comienzo del $D e$ senectute - hallaba que el imperio romano, más que ningún otro, había propagado juntamente con el dominio la lengua latina. Nebrija, negando la peculiar situación de Roma, asienta que las lenguas se difunden juntamente con los imperios, y con ellos mueren. $Y$ redondeando la frase de micer Gonzalo "la fabla comúnmente, más que todas las otras cosas siguen al imperio», acuña la afortunada fórmula: «siempre la lengua fue compañera del imperio». Extendiendo luego a la lengua de Roma el ciclo de nacimiento, florecer y decadencia común a los hombres y a sus creaciones políticas, reseña la vida de los imperios hebreo, griego y romano. Nuestros estudiosos suelen ver en las palabras puestas en boca

1 Exhumado por Mrguki, AR'rigas en su discurso de entrada en la Academia Española, Madrid, 1933, debe, sin embargo, consultarse en el estudio de F. HUARTE, Un vocabulario castellano, RFE, XXXV, 195I. Sobre el menosprecio al "pueblo común y grosero", consúltese en especial las pp. 319-27. 
de fray Hernando de Talavera un presagio de los descubrimientos y conquistas americanas. Así será, aunque las frases «leies quel vencedor pone al vencido", "pueblos bárbaros i naciones de peregrinas lenguas" acaso apunten a la reconquista de Granada y a las proyectadas empresas africanas. Las palabras de Nebrija tienen un son romano y bélico más que evangélico.

Antonio de Nebrija colocó la lengua en la vía central de la historia. I a lengua acompaña al proceso orgánico de la suprema creación del hombre: el Estado, con el que florece y se marchita. Antinomia aparente, más que real, es el pretender y reclamar que la gramática fije el lenguaje, 1o perpetúe e inmortalice deteniendo el fluir del tiempo. Las contrapuestas afirmaciones -organicismo e inmortalidad-se conciliaban en la mente del humanista, como la astrología y el libre albedrío. Ya Dante imaginaba que el latín "había sido fijado convencionalmente para ofrecer un lenguaje inmutable, libre del constante cambio inevitable en el hablar cotidiano" ${ }^{1}$. Igualmente Nebrija quiso "reduzir en artificio este nuestro lenguaje castellano para lo que agora i de aquí adelante en él se escriviere pueda quedar en un tenor i estenderse en toda la duración de los tiempos que están por venir" (Gramática, p. 9). Esta perennidad serviría a la gloria de los reyes y echaría los cimientos de una historiografía nacional duradera.

A pesar de todo, cuando años más tarde compuso su Rerum a Ferdinando et Elisabe... regibus gestarum decades duas -no impreso hasta I545- escribió en latín. En esta lengua atacó a los historiadores italianos tildándolos de envidiosos de las glorias españolas, y al humanismo, italiano que, si no se vigilaba cuidadosamente, corrompería a España. $\mathrm{I}_{10}$ anuncia en el prólogo, escrito en ${ }_{509}$ bajo el título de Divinatio. En la Exhortatio ad lectores acepta una teoría científica que equivale alepitafio de Roma. E1 Imperio, por una ley histórica, se desplaza de Oriente a Occidente. Los hispanos, siguiendo el movimiento del cielo, envían flotas que están a punto de enlazar el último Oriente con el Occidente, guerrean con los isleños de las Indias difundiendo la religión de Cristo ${ }^{2}$.

Paulatinamente vemos esbozarse un sentimiento hispánico - no me

1 R. A. HALI, ob. cit., p. I2. La idea de Nebrija acerca de la fijación de las lenguas vulgares mediante la gramática es adoptada en Italia por Sperone Speroni, Diálogo delle lingue (vide G. MARGrot' A, Origini italiani della "querelle des anciens", Roma, 1953, p. 102).

2 Rerum gestarum..., sig. Aiii ss. (Granada, 1545). NEBRIJA habia expresado en la Muestra de la istoria de las antigïedades de España, Burgos ca. 1499 (véase el Apéndice a la edición de la Gramática castellana, ed. de GoNZaL,ez ILUBERA, Oxford, I926, pp. 210-I I, esta vieja concepción: «Assí como con el movimiento del 
atrevo a llamarle teoría - que arraigará. Siendo la lengua la más inmediata expresión del valor de la persona y siendo los hispanos señores del mundo por su personal superioridad, la lengua de Castilla o Portugal será la más noble de todas. Este sentimiento despunta ya en Las valencianas lamentaciones, poema del cordobés Luis de Narváez compuesto entre I5Io-I5I5 y dedicado al Gran Capitán Gonzalo de Córdoba. En el capítulo II, De la gramática que observa el autor y de la perfección de la lengua castellana, contrariando la vulgar opinión de que los latinos ison los más altos et dignos / de vencer por oración", sostiene la superioridad de los griegos sobre los latinos, y la de los españoles sobre los griegos:

Cuanto los hábitos son de mayores perfecciones tanto sus pronunciaciones son de mayor perfección. Pues, ¿quién la generación de los nuestros vence o sobra?...

No solo nos son tractables las tierras que conquistamos mas los mares navegamos que fueron innavegables. Pugnamos quasi impugnables, a ninguno obedescemos salvo a Dios por quien tenemos las victorias memorables...

Por lo qual se muestra cierto que nuestras pronunciaciones tienen por muchas razones grandeza, gracia y concierto. ${ }^{1}$

Este sentido de primacía personal que confiere superioridad a esa genuina y primaria exteriorización del hombre que es la lengua, anima la Gramática da linguagem portuguesa, Lisboa, I536, obra del batallador, malhumorado y original filólogo que fue Fernão de Oliveira. En ella la utilización inconfesada y casi inadvertida hasta hoy de los gra-

cielo todos los reinos i monarchias començaron en levantẻ y por las Indias i Assirias, i después por la Grecia i Italia fenecieron en el ponientey) HARRI MEIER, Spanische Sprachbetrachtung und Geschichtschreibung am Ende des XV. Jahrhunderts, $R F, 49$, 1935, pp. I-20, recuerda que esta idea se halla ya en Otto von Freising.

1 JUAN DE NARVAeZ, Las valencianas lamentaciones, Sevilla, I889, páginas I7-I9. 
máticos italianos y españoles se une, y no sé si se disimula, con una decidida, desmedida afirmación de la originalidad y superioridad de la gente y el habla portuguesa.

Poseía Oliveira una mente aguda, un poco ofuscada por su cerrado nacionalismo y su combatividad. Los fonetistas - por ejemplo, I. S. Révah, a cuya autoridad me adhiero- suelen alabar sus descripciones de la pronunciación portuguesa, sus observaciones desperdigadas sobre fenómenos típicos de la lengua nativa, como la variedad de los diptongos. Oliveira, aún más decididamente que Nebrija, afirma que el uso es la ley de la lengua, aunque mal puede esconder su gusto por los arcaísmos aldeanos. "Os homẽs fazen a lingoa e não a lingoa os homẽs», frase cuya primera parte repetirá J. Ferreira de Vasconcelos, Comédia Eufrosina, poniéndola en boca de Joam d'Esperadeos ${ }^{1}$. Asegura que uprima é a natureza dos nossos homẽs, porque ella por sua vontade busca e tem de seu a perfeyção da arte que outras nações aquirem com muyto trabalho» (p. I4) y por ello su lengua "é principal antre muitas» (p. I5). Se da perfecta cuenta del valor político de la lengua, símbolo y cohesión del Imperio uporque a unidade della he muito certo apellido do reyno, do senhor e da irmandade dos vassalos" (página 69). Arremete contra todo lo que huela a latinismo o castellanismo, llegando a rechazar como castellana la antiquísima expresión portuguesa «el-Rei». Aconseja a sus compatriotas el aislamiento cultural: «Nam trabalhemos em lingua estrangeira mas apuremos tanto a nossa com boas doutrinas que possamos ensinar a muytas outras gentes e sempre seremos dellas louvados e amados, porque a semelhança é causa do amor e mays em as linguas» (p. 24). O como antes había dicho abreviadamente: «Milhor he que ensinemos a Guine ca que sejamos ensinados de Roma» (p. 2I).

Claro que él mismo no practica estos desaforados consejos, hijos de su natural hiperbólico. Conocía y utilizaba tanto los gramáticos latinos como los italianos y españoles, aunque a los modernos no los citase sino para combatirlos.

Aplica al imperio portugués actual y futuro lo que de Roma pregonaba Valla: vive y vivirá en la medida que enseña su lengua y adoctrina a los sometidos. Las Elegantiae ensalzaban a Roma como protectora de los letrados y sabios: Oliveira, arrancando en dirección contraria,

1 Fernao de Oliveira, Gramática da lingoagem portuguesa, ed. de SA NoGUEIRA, Lisboa, I933, p. 22. En mi edición de la Comédia Eufrosina, Madrid, I95 I, la reminiscencia está en la p. 8. 
niega el mecenazgo de Roma y proclama que sólo Portugal, especialmente desde Don João III, ha sabido ampararlos (pp. 23-24). No menciona Oliveira su deuda hacia el Trissino - que en I524 publica su Epistola delle lettere nuovamente aggi unte nella lingua italiana- aunque le tome su propuesta de distinguir e grande y e pequeno, o grande y o pequeno, como puede descubrir quien hojea la disertación de L. Kukenheim ${ }^{1}$. No alude al libro de Pietro Bembo, Prose della vulgar lingua, 1525, aunque, según imagino, no ignora su doctrina de que el uso perfecciona las lenguas (p. 22). No menciona a Castiglione, si bien sospecho que de $I l$ cortegiano, 1529, sacó algunas sugestiones y dichos, como aquel en que censura a los portugueses, que "como chegão a Toledo, logo se não lembrã da sua terra a que muito devem. E em vez de apurarem a sua lingua, corrompenna com emprestilhos» (p. 26). Lo que me huele a rastro de aquel pasaje de $I l$ cortegiano en que Castiglione ridiculiza a los lombardos, sus coterráneos, «i quali, se sono stati un anno for di casa, ritornati subito cominciano a parlare romano, talor spagnolo e francese, e Dio sa come» ${ }^{2}$.

A Nebrija le cita una vez sola para reprenderle, aunque su huella se revela en detalles menudos, y aunque le apreciase tanto que entre sus manuscritos aparece copiada la Gramática castellana en la Bibliothèque Nationale de París ${ }^{3}$. Haría falta una minuciosa inquisición para decidir cuándo explota sus lecturas como arsenal, cuándo como muro de rebote al que lanzar sus pelotas.

Cegado por sus prejuicios se indigna con los que buscan a las palabras portuguesas etimologías extranjeras, o con los que atribuyen a Pelayo el de Asturias la iniciativa de la reconquista que, según la leyenda del abad João de Montemor, se inició en Portugal.

En realidad su pecado más gordo son sus malos modales. Sus negaciones arrancan de la más positiva de las actitudes: el amor a la lengua de su patria y la decisión de estudiarla no como vago remedo de la latinidad, o mero resultado de una "corrupción", sino como creación original del genio patrio. Y le agradecemos su osada exploración emprendida a fin de que «a lingua de tam nobre gente e terra como he Portugal vivera contente e folgara de se estender pollo mundo" (p. I4).

1 L. KUKENHEMM, Contributions à l'histoire de la grammaire italienne, espagnole et française d l'époque de la Renaissance. Amsterdam, r932, pp. 37-4I.

2 B. Castiglione, Il cortegiano, ed. de V. CiAN, Florencia, 1929, pp. 69-70.

2 A. MOREL,FATIO, Manuscrits espagnols et portugais, Paris, I892, p. 249, Ms 5. 3 . 
João de Barros no recata los préstamos que toma a sus antecesores, ni aborrece su herencia cultural. Si, por no ser costumbre, no subraya sus deudas, no se afana por velarlas o por llevar la contraria a sus precursores. En su Cartinha y Gramática da lingua portuguesa, completadas por el Diálogo em louvor da lingua portuguesa ${ }^{1}$, el cual corresponde a los prefacios solemnes de Valla y Nebrija, sacrificó los vuelos teóricos a la intención práctica. Quería desterrar de las escuelas aquella desatinada pedagogía que enseñaba el latín con el Arte de Pastrana o con el Ars de Estevão Cavaleiro (Anselmo, núm. 557), e iniciaba en las letras primarias mediante la lectura de fórmulas procesales semejantes a la Forma libellandi, de Juan Infante, tan difundida en España, y al Tractado da forma dos libellos, de G. Martins Caminha, que, tardío fruto de esta rutina, se reimprime en Portugal a partir de 1549 (Anselmo, núm. 266).

Como Valla y Nebrija, ve el papel de la lengua en la cimentación del Imperio, pero le conmueve más su porvenir como instrumento de la evangelización en que los súbditos aprenderán la doctrina del Evangelio y rezarán a Cristo. En el Diálogo recuerda, por haberlo leído en las Elegantiae, que los romanos apuraron su lengua y que «açerca delles mais se estimava a victoria que a sua lingua tinha en ser recibida de todalas barbaras nações que de as someter ao jugo do seu imperio ii o mais çerto sinal que o Romano pode dar ser Espanha sudita ao seu imperio, nã serã suas coronicas e escrituras... mas a sua linguagem que nos ficou em testimunho de sua vitoria... Leixou a lingua latina este sinal do seu imperio que durará eternalmente» (pp. 228-29). Hasta aquí esta repetición, desde el ángulo portugués, de la introducción a las Elegantiae habría ufanado a Valla. Quizá le habría gustado menos la elocuente continuación en la que encauza el agua hacia los problemas e ideales del Portugal de Don João III: "As armas e padrões postos en Africa e em Asia e em tantas mil ilhas fora da repartiçam das tres partes da terra, mateariaes sam e podeas o tempo gastar: pero nã gastará doutrina, costumes, linguagem que os portugueses nestas terras leixarem». Animado por el entusiasmo de su hijo, continúa (p. 230): "Çerto he que nã á hy gloria que se possa comparar a quando os minimos Ethiopas, Persianos, indos daquẽ e dalẽ do Gange, em suas proprias terras, na força de seus templos e pagodes onde nunca se ouvio o nome romano, por esta nossa arte aprenderem a nossa linguagem, com que possam ser doutrinados

1 Cito las tres obritas por la reimpresión JOAO DF BARros. Compilação de vavias obras, I,isboa, 1785 . Tirge reeditar $y$ anotar estos documentos. 
em os preceitos da nossa fe que nella vam escritos» ${ }^{1}$. Frases en que una nota religiosa se mezcla a las ufanías patrióticas de Nebrija: «después que Vuestra Alteza metiesse debaxo de su iugo muchos pueblos bárbaros... y con el vencimiento aquellos ternían necessidad de recibir las leies quel vencedor pone al vencido i con ellas nuestra lengua, entonces por esta mi Arte podrian venir en el conocimiento della" (Gramática castellana, página II).

Tiene aspectos originales, por ejemplo, su aceptación del neologismo venido de U1tramar, porque sin duda veía claro, desde su puesto en la Casa da India, que aún en el terreno cultural existía entre metrópoli e imperio el intercambio fecundo, el comercio inevitable ${ }^{2}$. La lengua se enriquecía con el botín de otras culturas.

Volvamos la vista y resumamos el terreno recorrido. En Lorenzo Valla la defensa del oficio junto con el anhelo de consolarse de la decadencia política de una Italia subyugada por extranjeros, lleva a desvalorizar las armas y la acción frente a las letras y la cultura lingüística que perpetúan y eternizan la historia. Micer Gonzalo, en vísperas de la expansión española, considera la unidad lingüística como ineludible acompañamiento y gala de la unidad política. Nebrija redondea la feliz fórmula de su antecesor, inserta la lengua en el juego de fuerzas cósmicas que rigen los imperios y saca las consecuencias prácticas en su Gramática. Los portugueses, para quienes el imperio y la expansión son en ${ }_{53} 6$ hechos consumados, dan otro sesgo al tópico. Oliveira, que estima la lengua como producto natural de la personalidad nacional, se esfuerza por alejarla de los riesgos de la cultura extranjerizada y convertirla en un instrumento político que ligue a la metrópoli con las colonias. Por último, João de Barros, más confiado en el propio destino, abre las puertas

1 Alude a la Cartinha que realmente fue utilizada por San Francisco Javier para adoctrinar a los muchachos de la India. En el prólogo al príncipe Don Felipe glorifica igualmente la lengua maternal y el imperio "que como hũ novo apostolo, na força das mesquitas e pagodes de todalas seitas e idolatrias desprega pregando e vencendo as reaes quinas de Christo com que muitos povos da gentilidade sam metidos em o curral do senhor». La finalidad pedagógica de guiar los primeros pasos de muchachos que iban a cursar la lengua de César quizá le haya empujado a subrayar las semejanzas entre el idioma patrio y el de Roma. HeRnani CrDade en su interesante estudio João de Barros. O que pensa da lingua portuguesa (en Miscelânea... $F$. A. Coelho, Lisboa, r950, II, pp. 283 ss.) deslinda finamente los matices de su latinismo.

2 Gramática da lingua portuguesa, pp. 224-5. Es interesante comparar la actitud imperial de Barros con la de Gonzalo Hernández de Oviiedo, como él historiador de los descubrimientos. Oviedo, al componer la Historia general y natural de 
a la cultura de su época y señala a la lengua portuguesa la finalidad inmediata de difundir el cristianismo; es decir, lo que estimaba la flor y nata de su civilización.

\section{Eugenio Asensio.}

las. Indias en el libro I, escrito antes de 1535 (Madrid, I85I, I, p. 5), siente estrechos los términos del habla de la corte y de Toledo, justificando asi sus neologismos: «Si algunos vocablos extraños e bárbaros aquí se hallaren, la causa es la novedad de que se tracta, y no se pongan a la cuenta de mi romance: quen Madrid nasci, y en la casa real me crié, y con gente noble he conversado e algo he leido, para que se sospeche que avré entendido mi lengua castellana, la qual de las vulgares se tiene por mejor de todas». 